\title{
Validity of Bioelectrical Impedance Analysis for Older Amputees with Leprosy
}

\author{
Jihyun Lee, R.D., Ph.D. ${ }^{1,2}$, Seorin Doo, R.D., M.S. ${ }^{1}$, Yeonhee Lee, R.D., M.S. ${ }^{1}$, Jaeyoung Ahn, R.D., M.S. ', \\ Yookyoung Park, Ph.D. ${ }^{2}$, Hyun Joo Shin, R.D., M.S. ${ }^{3}$, Jae-myeong Lee, M.D., Ph.D. ${ }^{4}$
}

${ }^{1}$ Food Service and Clinical Nutrition Team, Ajou University Hospital, Suwon, ${ }^{2}$ Department of Medical Nutrition, Graduate School of East-West Medical Science, Kyung Hee University, Yongin, ${ }^{3}$ InBody Co., Ltd. InBody Bldg., ${ }^{4}$ Division of Acute Care Surgery, Department of Surgery, Korea University Anam Hospital, Korea University College of Medicine, Seoul, Korea

Purpose: Bioelectrical impedance analysis (BIA) evaluates body composition and electrical resistance according to weight and height but assumes all limbs are intact. This study evaluated the validity and accuracy of BIA in older amputees with leprosy.

Materials and Methods: We evaluated BIA's effectiveness for determining body composition by measuring muscle mass, water percentage, and physical resistance, including phase angle, in older amputees with leprosy. BIA was performed on 42 individuals with leprosy aged $\geq 65$ years. Comparative analyses were performed by amputation types (left lower limbs, right lower limbs, bilateral lower limbs, and non-amputees). Twenty people without leprosy or amputations of similar age, height, and weight were considered controls.

Results: Between the controls, amputee, and the controls without leprosy, BIA showed significant mean differences in skeletal muscle mass $(22.5 \pm 5.6 \mathrm{~kg}, 19.6 \pm 5.6 \mathrm{~kg}, 18.2 \pm 3.9 \mathrm{~kg}$, respectively; $\mathrm{P}=0.037)$; whole-body extracellular water $(\mathrm{ECW})$ ratios $(0.410 \pm 0.011,0.401 \pm 0.007,0.393 \pm 0.009$, respectively; $\mathrm{P}<0.001)$ and phase angle $(4.2 \pm 1.2,4.4 \pm 0.7$, $5.0 \pm 0.8$, respectively; $\mathrm{P}=0.029$ ). The bilateral lower limb amputation group (median, 0.415 ; range, $0.407-0.426$ ) showed significantly higher whole-body ECW values than the non-amputee group (median, 0.401, range: 0.391-0.415) $(\mathrm{P}=0.013)$. Right leg lean mass was highest in the right lower limb amputation group, followed by bilateral lower limb amputation, non-amputee, and left lower limb amputation groups (median: 9.86, 6.04, 5.02, 3.95, respectively, $\mathrm{P}=0.001$ ). As the length of the amputated lower limb was shortened, the lower limb's impedance decreased. However, BIA was evaluated without reflecting the shortened length, resulting in an error in the skeletal muscle mass readings.

Conclusion: Phase angle, ECW ratio, and bioelectrical impedance vector analysis obtained by BIA appeared accurate, but the skeletal muscle mass showed significant errors for amputated areas.

Keywords: Body composition, Amputee, Leprosy, Bioelectrical impedance, Bioelectrical impedance vector analysis

\section{INTRODUCTION}

Bioelectrical impedance analysis (BIA) estimates body composition by using electrical conductivity to detect impedance from different biological tissues.[1] BIA measures total body water (TBW) by obtaining the impedance index $(Z$ index $=$ height $^{2} / Z$ [impedance]). The " $Z$ " value was obtained by dividing the impedance, generated by applying weak alternating currents to the body through conductive materials such as water and electrolytes, by the squared value of height

Received April 16, 2021; Revised May 31, 2021; Accepted June 4, 2021

Corresponding author: Jae-myeong Lee

E-mail ljm3225@hanmail.net (iD ORCID https://orcid.org/0000-0001-5494-0653

This research received funding from the Ajou Translational Research Fund 2015 from Ajou University Hospital, Suwon, South Korea.

(c) (9) This is an Open Access article distributed under the terms of the Creative Commons Attribution Non-Commercial License (http://creativecommons.org/licenses/ by-nc/4.0), which permits unrestricted non-commercial use, distribution, and reproduction in any medium, provided the original work is properly cited. 
(TBW $=\rho \times Z$ index).[2] Body fat was determined by applying the ratio of lean body mass $(0.732)$ to body water, determining the lean body mass, and then subtracting the lean body mass from the body weight.[3]

BIA assumes that the body is one large cylinder with all limbs intact and measures the electrical resistance based on weight and height. Therefore, we would expect BIA results to be inaccurate for amputees, but conclusive research in this area is lacking. Therefore, this study was designed to examine the accuracy of BIA in individuals after an amputation.

In Western populations, peripheral vascular disease is the most common cause of amputations and currently accounts for $80 \%$ of amputees; however, in Korea, there are no accurate statistical data regarding this topic. According to one study, the most common cause of lower limb amputation in Korea was injuries caused by wars, such as the Korean War and Vietnam War, industrial accidents, and traffic accidents. [4] For this study, Sorokdo or Sorok Island, first used by Protestant missionaries as a sanatorium in 1910, was chosen as a location to hopefully recruit an amputee cohort to participate in this research. The island also has a painful history as this location was used to forcefully separate and house of people with leprosy during the Japanese colonial era.

Leprosy is a chronic infectious granulomatous disease caused by Mycobacterium leprae, the only known pathogenic bacteria with the ability to invade the peripheral nerves.[5] Despite treatment, patients with leprosy may experience severe and irreversible traumatic damage to the peripheral nerves causing disability due to persistent immune reactions. Even after $M$. leprae has been eliminated, wounds on the hands and feet are naturally or therapeutically amputated because of sensory, autonomic, and motor dysfunctions due to peripheral nerve damage. The resulting disability limits one's physical activity and social participation.[5] The World Health Organization (WHO) estimates that approximately 25\% of patients with leprosy have disabilities due to amputation (World Health Organization 1970). Most current residents of Sorokdo are elderly patients over 65 years of age with inactive leprosy, and many are disabled due to amputations.

This study utilized BIA body composition results to evaluate body water and nutritional status from the impedance vector by grouping the elderly participants living in Sorokdo into amputees with leprosy, non-amputees with leprosy, and controls without leprosy or amputations. The purpose of this study was to validate the usefulness of BIA as a body composition in amputees.

\section{MATERIALS AND METHODS}

\section{Research participants}

This study was performed on Sorokdo Island on January 8 9, 2016 and included 43 individuals with leprosy aged $\geq 65$ years who requested body composition evaluations and nutritional diet counseling. Participants included amputees $(n=20: 16$ males, 4 females; mean age, 78.5 \pm 6.3 years) and non-amputees $(n=22$ : 13 males, 9 females; mean age, $78.0 \pm 7.4$ years). We also analyzed body composition by dividing into subgroups of the left lower limb amputation $(n=6)$, right lower limb amputation $(n=10)$, bilateral lower limb amputation $(n=4)$, and non-amputee groups $(n=22)$. The control group $(n=20$ : 10 males, 10 females; mean age, $75.3 \pm 3.8$ years) included non-amputees without leprosy within the same age and height ranges of participants who were examined using the same BIA protocol (Fig. 1).

To determine nutritional status, participants completed the subjective global assessment (SGA) form and were classified into well-nourished, moderately malnourished, and severely malnourished groups. For the functional ability assessment, the participants were classified as having "No dysfunction" if they could live independently, "Working suboptimally" if they needed help from others in daily life, and "Bed ridden" if they remained in bed all day.

\section{Anthropometric measurement}

We obtained participant information from the medical records at Sorokdo Hospital regarding sex, age, and amputation status. Height and weight were measured during a home visit. For participants with prosthetic legs, we measured the participant's weight with the prosthetic leg in place, then measured the weight of the prosthetic leg and subtracted it from the body weight to obtain the individual's actual weight without the prosthetic leg. Amputation length was obtained by measuring the lengths of the non-amputated leg and the amputated leg and calculating the difference. Leg length was measured from the point of the anterior superior iliac spine to the sole of the foot with the participant lying on the floor, arms spread at $15^{\circ}$ with the backs of the hands upward and soles of the feet upright with the heels on the floor.

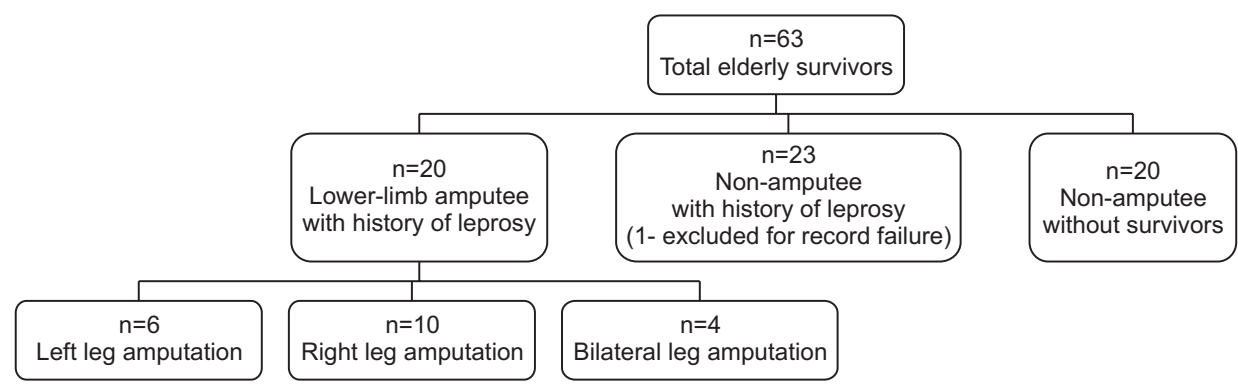

Fig. 1. Flow diagram of the participant recruitment process. 
The mean BMI of the amputee group was determined using the estimated body weight (weight before amputation[weight before amputation $\times$ proportion of total body weight represented by missing limb segments]) by Osterkamp (1995).[6] Regarding the contributions of the individual body parts in terms of the percentage of total body weight, the mean for the lower leg in the amputee group was 5.3\%, while that for the foot was $1.8 \%$ based on a $23.5 \%$ amputation of the length of the lower leg and foot, as reported by Brunnstorm et al.(1983).[7]

\section{Body composition evaluation}

The participants remained in a supine position for $10 \mathrm{~min}$ utes with their arms and legs slightly spread while the BIA body composition test was performed. This study used a portable BIA device (InBody S10; InBody Co., Ltd., Seoul, Korea). The test was performed using physical contact stickers connecting the electrodes to 8 specific locations (one on the most distal part of the third metacarpal bone of each hand, one on each wrist, one on the most distal part of the second metatarsal bone in each foot, and one on the central part of each ankle) after the electrodes were cleaned with alcohol

Table 1. Baseline characteristics of study participants with leprosy

\begin{tabular}{|c|c|c|c|c|}
\hline \multicolumn{2}{|c|}{ Patient characteristic } & $\underset{(n=20)}{\text { Amputation }}$ & $\begin{array}{c}\text { No amputation } \\
(n=22)\end{array}$ & P-value \\
\hline \multicolumn{2}{|l|}{ Sex (males) ${ }^{\dagger}$} & $16(34.5)$ & $13(44.8)$ & 0.203 \\
\hline \multicolumn{2}{|l|}{$\operatorname{Age}(y)^{\ddagger}$} & $78.5 \pm 6.3$ & $77.9 \pm 7.4$ & 0.817 \\
\hline \multicolumn{2}{|l|}{ Height $(\mathrm{cm})^{\ddagger}$} & $155.2 \pm 10.7$ & $153.0 \pm 7.6$ & 0.440 \\
\hline \multicolumn{2}{|c|}{ Weight $(\mathrm{kg})^{\dagger}$} & $53.4 \pm 11.4$ & $54.9 \pm 8.4$ & 0.632 \\
\hline \multicolumn{2}{|c|}{ Estimated weight $(\mathrm{kg}) / \mathrm{BMI}\left(\mathrm{kg} / \mathrm{m}^{2}\right)$} & $57.5 / 23.9$ & NA/23.4 & \\
\hline \multicolumn{2}{|c|}{ Years post-amputation ${ }^{\ddagger}$} & $26.4 \pm 16.5$ & NA & \\
\hline \multicolumn{2}{|l|}{ Intact limb $(\mathrm{cm})^{\dagger}$} & $79.5 \pm 6.3$ & NA & \\
\hline \multicolumn{2}{|l|}{ Amputated limb $(\mathrm{cm})^{\dagger}$} & $60.8 \pm 5.9$ & NA & \\
\hline \multirow[t]{5}{*}{ Cause of amputation } & Ulceration \& infection & $8(33.3)$ & NA & \\
\hline & Contracture of joint & $4(16.6)$ & & \\
\hline & Accidents & $3(12.5)$ & & \\
\hline & Burn & $3(12.5)$ & & \\
\hline & Other & $6(25.0)$ & & \\
\hline \multirow[t]{12}{*}{ Comorbid Conditions $^{\dagger}$} & Hypertension & $5(35.0)$ & $8(36.4)$ & 0.927 \\
\hline & Arthritis & $4(20.0)$ & $7(31.8)$ & 0.384 \\
\hline & Osteoporosis & $5(25.0)$ & $6(27.3)$ & 0.864 \\
\hline & Cancer & $4(20.0)$ & $6(27.3)$ & 0.580 \\
\hline & Gastrointestinal disease & $3(15.0)$ & $5(22.7)$ & 0.524 \\
\hline & Spinal disease & $4(20.0)$ & $3(13.6)$ & 0.580 \\
\hline & Stroke & $2(10.0)$ & $4(18.2)$ & 0.449 \\
\hline & Diabetes mellitus & $0(0.0)$ & $3(13.6)$ & 0.087 \\
\hline & Dyslipidemia & $0(0.0)$ & $3(13.6)$ & 0.087 \\
\hline & Other & $10(50.0)$ & $8(36.4)$ & 0.372 \\
\hline & Vision impairment & $3(15.0)$ & $3(13.6)$ & 0.900 \\
\hline & Hearing impairment & $2(10.0)$ & $4(18.2)$ & 0.449 \\
\hline \multirow[t]{3}{*}{ Functional ability $^{\dagger}$} & No dysfunction & $11(55.0)$ & $10(45.5)$ & 0.416 \\
\hline & Working suboptimally & $8(40.0)$ & $12(54.5)$ & \\
\hline & Bed ridden & $1(5.0)$ & $0(0.0)$ & \\
\hline \multirow[t]{3}{*}{ Subjective global assessment $^{\dagger}$} & Well-nourished & $8(40.0)$ & $16(72.7)$ & $0.045^{*}$ \\
\hline & Moderately malnourished & $9(45.0)$ & $6(27.3)$ & \\
\hline & Severely malnourished & $3(15.0)$ & $0(0.0)$ & \\
\hline
\end{tabular}

${ }^{\dagger}$ Number (\%), by chi-squared test, ${ }^{*}<.05$

${ }^{\dagger}$ Mean \pm SD.

$\mathrm{NA}=$ not applicable. 
cotton swabs. We placed two electrodes to the distal part of the in amputated limb at a distance of about $10 \mathrm{~cm}$ in parallel towards to body.

\section{Statistical analysis}

This study analyzed the collected data using SPSS Statistics version 23.0 (IBM, Armonk, New York, USA). The means and standard deviations for age, BMI, and body composition were compared between the amputee and non-amputee groups using t-tests. The impedance and phase angle of the control (without leprosy or amputations), amputee, and nonamputee groups were analyzed using one-way analysis of variance and the distribution on the R-Xc graph method was examined by bioelectrical impedance vector analysis (BIVA). It was analyzed using R 3.6.1 (Open Source License) as statistics in BIVA. Kruskal-Wallis tests were performed to analyze body composition according to amputation type. The statistical significance of all the results were verified based on a P-value $<0.05$. For post-hoc analysis, the Mann-Whitney $U$ test using Bonferroni's method was performed and the relative statistical significance between the groups was $\mathrm{P}<0.0083$ (0.05 for 6 comparisons).

\section{Research involving human participants and/or animals}

All analysis performed in studies involving human participants were in accordance with the ethical standards of the institutional and/or national research committee (AJIRB-DEVDE4-15-115) and with the 1964 Helsinki declaration and its later amendments or comparable ethical standards. Written informed consent was obtained from all individual participants included in the study.

\section{RESULTS}

\section{Characteristics of research participants}

The general characteristics of the participants with leprosy living in Sorokdo are summarized in Table 1. The control group included unaffected people of similar age and height to the participants in Sorokdo. A comparison could not be made due to a lack of information such as malnutrition status.

The mean length of the non-amputated leg in the amputee group was $79.5 \pm 6.3 \mathrm{~cm}$, while the mean length of the amputated leg including bilateral amputees was $60.8 \pm 5.9 \mathrm{~cm}$.

Table 2. Bioelectrical impedance analysis results

\begin{tabular}{|c|c|c|c|c|c|}
\hline \multicolumn{2}{|l|}{ 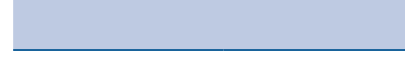 } & Amputation $(n=20)$ & No amputation $(n=22)$ & Control $(n=20)$ & P-value \\
\hline \multicolumn{2}{|l|}{ Age (y) } & $78.5 \pm 6.3(66.0 \sim 93.0)$ & $78.0 \pm 7.4(61.0 \sim 92.0)$ & $75.3 \pm 3.8(71.0 \sim 84.0)$ & 0.216 \\
\hline \multicolumn{2}{|l|}{ Weight (kg) } & $53.4 \pm 11.4(31.9 \sim 76.0)^{\mathrm{a}}$ & $54.9 \pm 8.4(40.1 \sim 69.1)^{\mathrm{a}, \mathrm{b}}$ & $61.1 \pm 9.6(41.2 \sim 75.8)^{\mathrm{b}}$ & $0.037^{*}$ \\
\hline \multicolumn{2}{|l|}{ Height (cm) } & $155.2 \pm 10.9(130.0 \sim 172.0)$ & $153.0 \pm 7.6(134.0 \sim 165.0)$ & $158.5 \pm 10.0(142.8 \sim 176.2)$ & 0.180 \\
\hline \multicolumn{2}{|c|}{ Body mass index $\left(\mathrm{kg} / \mathrm{m}^{2}\right)$} & $22.0 \pm 3.5(15.1 \sim 29.0)$ & $23.4 \pm 3.0(17.9 \sim 30.6)$ & $24.3 \pm 2.8(19.6 \sim 30.3)$ & 0.078 \\
\hline \multicolumn{2}{|c|}{ Percent body fat $(\%)$} & $29.1 \pm 10.4(9.7 \sim 44.6)$ & $35.8 \pm 8.3(18.2 \sim 49.5)$ & $31.7 \pm 8.8(17.3 \sim 45.1)$ & 0.066 \\
\hline \multicolumn{2}{|c|}{ Skeletal muscle mass (kg) } & $19.6 \pm 5.6(9.5 \sim 29.8)^{\mathrm{a}, \mathrm{b}}$ & $18.2 \pm 3.9(12.0 \sim 26.2)^{\mathrm{a}}$ & $22.5 \pm 5.6(15.2 \sim 32.5)^{\mathrm{b}}$ & $0.028^{*}$ \\
\hline \multirow[t]{6}{*}{ ECW ratio } & Whole body & $0.410 \pm 0.011(0.392 \sim 0.431)^{\mathrm{a}}$ & $0.401 \pm 0.007(0.391 \sim 0.415)^{\mathrm{b}}$ & $0.393 \pm 0.009(0.378 \sim 0.408)^{\mathrm{c}}$ & $<0.001^{*}$ \\
\hline & Right arm & $0.385 \pm 0.007(0.374 \sim 0.406)^{\mathrm{a}}$ & $0.385 \pm 0.006(0.376 \sim 0.401)^{\mathrm{a}}$ & $0.380 \pm 0.004(0.372 \sim 0.387)^{\mathrm{b}}$ & $0.005^{*}$ \\
\hline & Left arm & $0.385 \pm 0.007(0.373 \sim 0.397)^{\mathrm{a}}$ & $0.385 \pm 0.005(0.377 \sim 0.394)^{\mathrm{a}}$ & $0.382 \pm 0.004(0.376 \sim 0.390)^{\mathrm{b}}$ & $0.042^{*}$ \\
\hline & Trunk & $0.406 \pm 0.010(0.388 \sim 0.420)^{\mathrm{a}}$ & $0.401 \pm 0.007(0.390 \sim 0.415)^{\mathrm{a}}$ & $0.392 \pm 0.010(0.377 \sim 0.408)^{\mathrm{b}}$ & $<0.001^{*}$ \\
\hline & Right leg & $0.415 \pm 0.014(0.374 \sim 0.436)^{\mathrm{a}}$ & $0.406 \pm 0.010(0.389 \sim 0.424)^{\mathrm{b}}$ & $0.397 \pm 0.012(0.375 \sim 0.419)^{\mathrm{b}}$ & $<0.001^{*}$ \\
\hline & Left leg & $0.418 \pm 0.017(0.385 \sim 0.452)^{\mathrm{a}}$ & $0.408 \pm 0.008(0.395 \sim 0.426)^{b}$ & $0.396 \pm 0.011(0.379 \sim 0.416)^{\mathrm{c}}$ & $<0.001^{*}$ \\
\hline \multirow[t]{6}{*}{ Phase angle $\left(^{\circ}\right)$} & Whole body & $4.2 \pm 1.2(2.1 \sim 7.1)^{\mathrm{a}}$ & $4.4 \pm 0.7(2.9 \sim 5.4)^{\mathrm{a}, \mathrm{b}}$ & $5.0 \pm 0.8(3.8 \sim 6.4)^{\mathrm{b}}$ & $0.029^{*}$ \\
\hline & Right arm & $4.6 \pm 1.2(2.5 \sim 6.9)$ & $4.7 \pm 0.9(2.5 \sim 6.5)$ & $5.1 \pm 0.7(4.0 \sim 6.3)$ & 0.170 \\
\hline & Left arm & $4.3 \pm 1.4(1.9 \sim 6.9)$ & $4.4 \pm 0.6(3.1 \sim 5.6)$ & $5.0 \pm 0.7(3.8 \sim 6.1)$ & 0.065 \\
\hline & Trunk & $4.8 \pm 1.0(3.0 \sim 6.9)$ & $5.1 \pm 0.7(3.1 \sim 6.2)$ & $5.5 \pm 1.1(3.1 \sim 7.8)$ & 0.075 \\
\hline & Right leg & $3.8 \pm 1.2(1.8 \sim 7.4)^{\mathrm{a}}$ & $4.1 \pm 0.9(2.5 \sim 6.0)^{\mathrm{a}, \mathrm{b}}$ & $4.8 \pm 1.1(3.0 \sim 6.9)^{\mathrm{b}}$ & $0.018^{*}$ \\
\hline & Left leg & $3.8 \pm 1.1(2.5 \sim 6.1)^{\mathrm{a}}$ & $4.0 \pm 0.8(2.5 \sim 5.1)^{\mathrm{a}}$ & $4.9 \pm 1.1(3.2 \sim 6.8)^{\mathrm{b}}$ & $0.001^{*}$ \\
\hline \multicolumn{2}{|l|}{$\mathrm{Xc} / \mathrm{Ht}(\Omega)$} & $27.2 \pm 5.5(16.8 \sim 37.6)^{\mathrm{a}}$ & $30.0 \pm 6.7(18.7 \sim 45.9)^{\mathrm{a}, \mathrm{b}}$ & $32.0 \pm 4.2(23.1 \sim 39.5)^{\mathrm{b}}$ & $0.031^{*}$ \\
\hline \multicolumn{2}{|l|}{$\mathrm{R} / \mathrm{Ht}(\Omega)$} & $387.5 \pm 79.2(260.7 \sim 531.9)$ & $392.2 \pm 95.5(269.6 \sim 664.3)$ & $374.6 \pm 69.6(266.6 \sim 505.0)$ & 0.780 \\
\hline
\end{tabular}

All values are mean \pm Standard deviation (range). All group values were tested by one-way analysis of variance (ANOVA) with Tukey's multiple comparisons test.

a,b,c Different letters represent significant differences $(\mathrm{P}<0.05)$ by ANOVA.

$\mathrm{BMI}=$ body mass index; $\mathrm{ECW}=$ extracellular water; $\mathrm{Z} / \mathrm{H}=\mathrm{impedance} /$ height; $\mathrm{Xc} / \mathrm{Ht}=\mathrm{reactance} /$ height; $\mathrm{R} / \mathrm{Ht}=\mathrm{resistance} / \mathrm{height}$. 
The mean amputation length was $18.7 \mathrm{~cm}$, which was equivalent to $23.5 \%$ of the total leg length. As a result of using the estimated weight as shown, the estimated body weight and BMI of the amputee group were $57.5 \mathrm{~kg}$ and $23.9 \mathrm{~kg} / \mathrm{m}^{2}$, respectively. There were no statistically significant differences in the types and frequencies of underlying diseases between the two groups of participants (not including controls). There were no subjects in our study with chronic heart failure or end stage renal failure that could bias BIA. From a functional aspect, $40.0 \%$ of the amputee group and $54.5 \%$ of the nonamputee group required assistance from others in their daily lives, while those participants with bed ridden status accounted for only $5.0 \%$ of the amputee group; no statistically significant inter-group difference was observed $(P=0.416)$. When comparing the nutritional status by the SGA, $45.0 \%$ of the amputees were moderately malnourished and $15.0 \%$ were severely malnourished, while $27.3 \%$ of the non-amputee group were moderately malnourished. There were significantly more cases of severe malnutrition in the amputee group $(\mathrm{P}=0.045)$.

\section{BIA results}

Skeletal muscle masses (SMM) obtained by BIAs were significantly higher in the control group $(22.5 \pm 5.6 \mathrm{~kg})$ than in the amputee $(19.6 \pm 5.6 \mathrm{~kg})$ and non-amputee groups $(18.2 \pm 3.9 \mathrm{~kg})$ and showed statistically significant differences $(P=0.037)$. The extracellular water $(E C W)$ ratio, an index of physical edema, was higher in the amputee group $(0.410 \pm 0.011)$ than in the non-amputee $(0.401 \pm 0.007)$ and control groups $(0.393 \pm 0.009)(P<0.001)$. ECW ratio of upper arms were 0.385 regardless of which lower limb was amputated, but the value was significantly higher than that of the control group. The phase angle values as well as the whole-body measurements were higher in the control group than in the non-amputee and amputee groups in all 5 categories. In addition, statistically significant differences were found among the three groups in the whole body and both lower limbs ( $P$ values for the whole body, right leg, and left leg: 0.029, 0.018, and 0.001, respectively) (Table 2).

The BIA results of the 4 groups according to amputation levels are summarized in Table 3. Comparisons of mean age, height, and weight by amputee type revealed that the right lower limb amputation group and non-amputee group were significantly taller $(P=0.008)$ and heavier $(P=0.022)$. There were no significant differences in ages or BMls among the 4 groups (Table 3). Median values of the heavier right lower

Table 3. Characteristics of body composition based on lower-limb amputation type

\begin{tabular}{|c|c|c|c|c|c|}
\hline & \multicolumn{3}{|c|}{ Amputation $(n=20)$} & \multirow{2}{*}{$\begin{array}{l}\text { No amputation } \\
(n=22)\end{array}$} & \multirow{2}{*}{$\begin{array}{l}\text { Kruskal-Wallis } \\
\text { test P-value }\end{array}$} \\
\hline & Left $(n=6)$ & Right $(n=10)$ & Both $(n=4)$ & & \\
\hline Age (y), Mean \pm SD & $76.5 \pm 6.3$ & $77.1 \pm 5.3$ & $84.8 \pm 6.0$ & $77.9 \pm 7.4$ & 0.227 \\
\hline Height $(\mathrm{cm})$, Mean \pm SD & $147.7 \pm 9.5^{\mathrm{b}}$ & $161.8 \pm 8.1^{\mathrm{a}}$ & $150.0 \pm 10.2$ & $153.0 \pm 7.6$ & $0.008^{*}$ \\
\hline Weight (kg), Mean \pm SD & $46.0 \pm 10.3^{\mathrm{b}}$ & $59.9 \pm 3.1$ & $48.3 \pm 8.2$ & $54.9 \pm 8.4$ & $0.022^{*}$ \\
\hline $\operatorname{BMI}\left(\mathrm{kg} / \mathrm{m}^{2}\right)$ & $20.7 \pm 3.4$ & $23.1 \pm 3.3$ & $21.4 \pm 4.4$ & $23.4 \pm 3.0$ & 0.284 \\
\hline Body cell mass (kg) & $20.0(12.6 \sim 30.7)$ & $27.6(19.8 \sim 34.9)$ & $20.2(15.1 \sim 23.0)$ & $21.4(15.3 \sim 31.0)$ & $0.003^{*}$ \\
\hline Bone mineral content $(\mathrm{kg})$ & $1.9(1.4 \sim 2.3)$ & $2.3(1.8 \sim 2.7)$ & $2.0(1.7 \sim 2.3)$ & $2.0(1.3 \sim 2.9)$ & $0.001^{*}$ \\
\hline $\begin{array}{l}\text { Total body water/ } \\
\text { fat free mass }(\%)\end{array}$ & $74.4(73.6 \sim 74.9)$ & $74.4(73.7 \sim 75.0)^{\mathrm{a}}$ & $74.0(72.9 \sim 74.4)$ & $73.8(72.7 \sim 74.7)$ & $0.017^{*}$ \\
\hline Protein $(k g)$ & $6.1(3.7 \sim 9.2)$ & $8.4(6.0 \sim 10.5)$ & $6.05(4.5 \sim 7.0)$ & $6.45(4.6 \sim 9.4)$ & $0.027^{*}$ \\
\hline Fat (kg) & $12.2(8.0 \sim 21.6)$ & $18.4(5.2 \sim 26.9)$ & $19.6(4.0 \sim 20.4)$ & $19.4(10.0 \sim 32.7)$ & 0.157 \\
\hline Mineral (kg) & $2.2(16.5 \sim 2.9)$ & $2.8(2.2 \sim 3.4)$ & $2.4(2.0 \sim 2.7)$ & $2.4(1.6 \sim 3.4)$ & 0.071 \\
\hline Skeletal muscle mass (kg) & $16.25(10 \sim 26)$ & $23.1(16 \sim 30)$ & $16.4(12 \sim 19)$ & $17.4(12 \sim 26)$ & $0.028^{*}$ \\
\hline Percent body fat (\%) & $30.3(15.3 \sim 38.0)$ & $30.9(9.7 \sim 42.1)$ & $36.8(10.7 \sim 44.6)$ & $37.2(18.2 \sim 49.5)$ & 0.138 \\
\hline Soft lean mass (kg) & $30.5(19.2 \sim 45.1)$ & $41.1(30.0 \sim 51.6)$ & $30.5(23.2 \sim 34.6)$ & $31.7(23.0 \sim 46.1)$ & $0.026^{*}$ \\
\hline Fat free mass $(\mathrm{kg})$ & $32.3(20.6 \sim 47.4)$ & $43.35(32.0 \sim 54.3)$ & $32.6(24.9 \sim 36.6)$ & $33.7(24.3 \sim 49.0)$ & $0.027^{*}$ \\
\hline Phase angle $\left(^{\circ}\right)$ & $3.9(3.2 \sim 7.1)$ & $4.5(3.2 \sim 5.9)$ & $3.6(2.7 \sim 4.8)$ & $4.5(2.9 \sim 5.4)$ & 0.362 \\
\hline Intra cellular water $(\mathrm{L})$ & $14.0(8.8 \sim 21.4)$ & $19.3(13.8 \sim 24.3)$ & $14.1(10.5 \sim 16.0)$ & $14.9(10.7 \sim 21.7)$ & $0.026^{*}$ \\
\hline Extra cellular water (L) & $10.1(6.4 \sim 13.5)$ & $13.0(9.8 \sim 16.1)^{\mathrm{a}}$ & $10.0(7.9 \sim 11.2)$ & $9.8(7.4 \sim 14.5)$ & $0.019^{*}$ \\
\hline Total body water (L) & $24.0(15.2 \sim 35.3)$ & $32.2(23.6 \sim 40.4)^{\mathrm{a}}$ & $24.0(18.4 \sim 27.2)$ & $24.9(18.1 \sim 36.2)$ & $0.026^{*}$ \\
\hline
\end{tabular}

All values are mean \pm SD or median (minimum maximum). All group values were tested by one-way analysis of variance (ANOVA) with the Bonferroni's multiple comparisons test.

${ }^{\mathrm{a}}$ Denotes significance from no amputation group.

${ }^{\mathrm{b}}$ Denotes significance from right lower-limb amputation group. 
limb amputation group were significantly higher for body cell mass (BCM), bone mineral content (BMC), TBW/fat-free mass (FFM), protein, SMM, soft lean mass (SLM), FFM, intracellular water (ICW), ECW, and TBW.

The whole-body ECW ratio median values, which reflect systemic edema conditions, were highest in the left lower limb amputation group, followed by the bilateral lower limb amputation, right lower limb amputation, and non-amputee groups $(0.417,0.415,0.403,0.401$, respectively, $\mathrm{P}=0.013)$ (Table 4). The ECW ratio was significantly higher in the right leg in the bilateral lower limb amputation (0.421) and right lower limb amputation (0.420) groups $(P=0.009)$. It was also significantly higher in the left leg in the bilateral lower limb amputation (0.425) and left lower limb amputation groups (0.427) $(\mathrm{P}=0.001)$.

Analysis of lean body mass by amputation levels revealed that the right lower limb amputation group, which consisted of participants of higher average heights and weights, showed significantly higher values in the right arm, left arm, trunk, right leg, and left leg. The right leg SLM was highest in the right lower limb amputation group $(P=0.001)$, the left leg SLM was highest in the left lower limb amputation group $(P=0.093)$, and the lower limb muscle mass of the bilateral lower limb amputation group was higher than that of the non-amputee group (Table 4).

\section{Impedance vector distributions of the amputee and non-amputee groups}

The impedance vector with directions corresponding to the sum of bioelectrical impedance and reactance for the control group showed binomial distribution parabolas at the 50th, 75th, and 95th percentiles (Fig. 2). Those of the nonamputee group were located at the 75th and 95th percentile parabolas, more than the amputee group, while most of the amputee group deviated from the 95th percentile parabola. The amputee group showed lower distributions in $\mathrm{R} /$ height (X-axis) and reactance $\left(\mathrm{Xc}_{\mathrm{c}}\right) /$ height (Y-axis) than the non-amputee group.

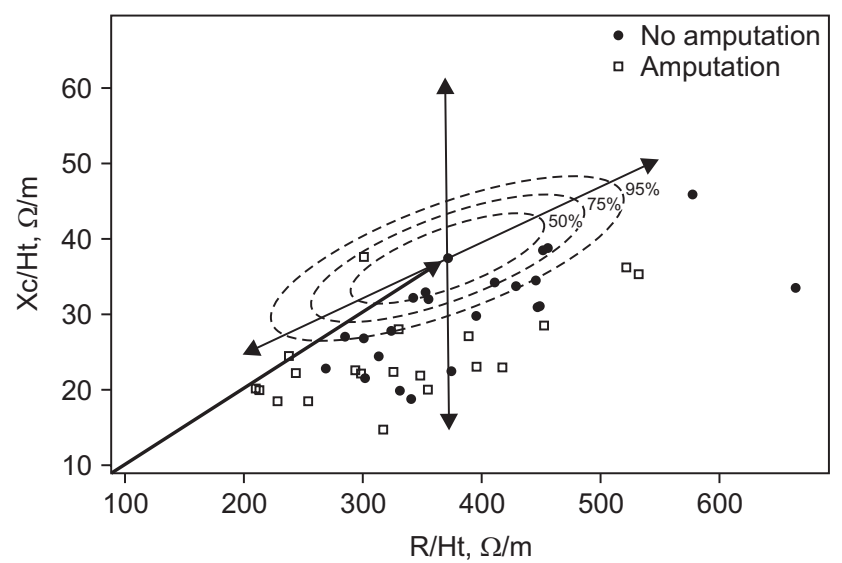

Fig. 2. Bioelectrical impedance vector analysis (BIVA) showing distribution of differences in bioelectrical impedance values.

Table 4. Extracellular water ratio and segment less mass for body composition alteration based on lower-limb amputation type

\begin{tabular}{|c|c|c|c|c|c|}
\hline & \multicolumn{3}{|c|}{ Amputation $(n=20)$} & \multirow{2}{*}{$\begin{array}{l}\text { No amputation } \\
\qquad(\mathrm{n}=22)\end{array}$} & \multirow{2}{*}{$\begin{array}{l}\text { Kruskal-Wallis } \\
\text { test P-value }\end{array}$} \\
\hline & Left $(n=6)$ & Right $(n=10)$ & Both $(n=4)$ & & \\
\hline \multicolumn{6}{|l|}{ ECW ratio } \\
\hline Whole-body & $0.417(0.392 \sim 0.431)$ & $0.403(0.393 \sim 0.416)$ & $0.415(0.407 \sim 0.426)^{\mathrm{a}}$ & $0.401(0.391 \sim 0.415)$ & $0.013^{*}$ \\
\hline Right arm & $0.389(0.374 \sim 0.390)$ & $0.382(0.377 \sim 0.392)$ & $0.388(0.379 \sim 0.406)$ & $0.385(0.376 \sim 0.401)$ & 0.737 \\
\hline Left arm & $0.389(0.374 \sim 0.392)$ & $0.382(0.373 \sim 0.392)$ & $0.391(0.383 \sim 0.397)$ & $0.385(0.377 \sim 0.394)$ & 0.317 \\
\hline Trunk & $0.412(0.390 \sim 0.420)$ & $0.400(0.390 \sim 0.420)$ & $0.412(0.400 \sim 0.420)$ & $0.400(0.390 \sim 0.420)$ & $0.050^{*}$ \\
\hline Right leg & $0.407(0.374 \sim 0.436)$ & $0.420(0.398 \sim 0.427)^{\mathrm{a}}$ & $0.421(0.411 \sim 0.428)$ & $0.404(0.389 \sim 0.424)$ & $0.009^{*}$ \\
\hline Left leg & $0.427(0.418 \sim 0.452)^{\mathrm{b}}$ & $0.402(0.385 \sim 0.428)$ & $0.425(0.411 \sim 0.440)^{\mathrm{a}}$ & $0.406(0.395 \sim 0.426)$ & $0.001^{*}$ \\
\hline \multicolumn{6}{|c|}{ Segmental lean body mass (Kg) } \\
\hline Right arm & $0.77(0.64 \sim 2.23)$ & $1.99(0.92 \sim 2.64)$ & $0.83(0.61 \sim 1.38)$ & $1.59(0.57 \sim 2.99)$ & $0.006^{*}$ \\
\hline Left arm & $0.77(0.40 \sim 2.20)^{\mathrm{c}}$ & $2.03(0.90 \sim 2.60)$ & $0.77(0.20 \sim 1.30)^{\mathrm{a}}$ & $1.62(1.00 \sim 2.50)$ & $0.002^{*}$ \\
\hline Trunk & $9.95(8.10 \sim 19.00)$ & $17.85(11.5 \sim 21.07)$ & $10.70(6.8 \sim 14.00)^{\mathrm{a}}$ & $15.10(10.8 \sim 20.80)$ & $0.003^{*}$ \\
\hline Right leg & $3.95(3.12 \sim 6.79)^{\mathrm{b}}$ & $9.86(6.45 \sim 14.29)^{\mathrm{a}}$ & $6.40(4.50 \sim 7.93)$ & $5.02(3.12 \sim 7.86)$ & $0.001^{*}$ \\
\hline Left leg & $8.58(1.13 \sim 13.50)$ & $6.43(3.83 \sim 7.88)$ & $4.85(3.74 \sim 7.49)$ & $4.78(2.56 \sim 7.92)$ & 0.093 \\
\hline
\end{tabular}

All values are median(minimum $\sim$ maximum).

${ }^{a}$ Denotes significance from non-lower-limb amputation group.

${ }^{\mathrm{b}}$ Denotes significance from right lower-limb amputation group.

${ }^{c}$ Denotes significance from both lower-limb amputation group.

ECW=extracellular water. 


\section{DISCUSSION}

The original purpose of this study was to verify the accuracy of BIAs for patients with amputations. The phase angle, ECW ratio, and BIVA among the BIA results were applicable to amputation patients but, the SMM values from BIAs in lower limb amputations showed estimated results that were higher than the actual values.

Since the majority of the participants were older than 75 years of age, it is possible that changes in body compositions of the elderly due to changes in physical conditions were reflected in the BIA results. In addition, although the participants were no longer in active leprous disease states, changes in their physical conditions due to long-term inactivity (mean $26.4 \pm 16.5$ years after lower limb amputation) may have been reflected in the BIA results. Nevertheless, the results of this study were analyzed in terms of amputations.

The energy consumption of patients with amputations is known to increase from $31 \%$ to $67 \%$ upon walking depending on the amputation level.[8,9] Therefore, participants in the amputee group were expected to weigh less than those in the non-amputee or control groups. In addition, the participants with leprosy were expected to weigh less or be malnourished compared to those in the control group. In a study by Rao and John [10] on the nutritional status of people with leprosy in India, a higher incidence of underweight and malnourishment (BMIs<18.5) was reported among people with leprosy than among the general population. The results of this study show that the mean weight of the individuals with leprosy was significantly lower than that of individuals in the control group and that the mean weight of the amputee group was significantly lower than that of the non-amputee group. These findings are consistent with the above hypothesis.

However, the mean BMI using estimated body weights of the amputee and non-amputee groups was similar: both groups were overweight by the standards of the Korean Society for the Study of Obesity. A comparative study of elderly survivors of leprosy and the general population, by Kim et al.,[11] also reported a BMI of $24.4 \pm 2.5 \mathrm{~kg} / \mathrm{m}^{2}$ in the elderly leprosy survivor group with a mean age of $74.4 \pm 6.9$ years. The Korean government has been providing leprosy patients with healthcare and welfare support. It was difficult to evaluate whether Sorokdo subjects were eating a balanced diet when visiting, but access to food materials was not difficult. In addition, the aging of Sorokdo patients might have affected weight gain as the subjects' mobility decreased and their metabolic rate dropped at the same time. On the other hand, in India, the gap between the rich and the poor is still big, and it is presumed that there has been no systematic management of leprosy patients.

Eckard et al.,[12] using dual-energy X-ray absorptiometry (DXA), observed body composition and metabolic changes during the first year after amputation in military service mem- bers and reported an increase in body fat due to leg muscle atrophy and decreased activity. Sherk et al.,[13] reported that the groups that received transfemoral or transtibial amputations had lesser lean body mass than the control group. This was attributed to muscle atrophy in the residual limb with larger relative amounts of body fat in the thighs, especially in patients with unilateral transfemoral amputations. In this study, the SMM values obtained from BIAs were highest in the control group, followed by the amputee and nonamputee groups $(22.5 \pm 5.6 \mathrm{~kg}, 19.6 \pm 5.6 \mathrm{~kg}$, and $18.2 \pm 3.9$ $\mathrm{kg}$, respectively; $\mathrm{P}=0.037$ ) (Table 2 ). We expected the group with leprosy to have a lower mean SMM than the control group. Our results were consistent with those of a previous study (sarcopenia incidence, $38.7 \%$ in people with leprosy vs. 5.6 in healthy population, $\mathrm{P}=0.002$ ) that reported the leprosy survivor group had a significantly higher prevalence of sarcopenia than the control group.[11] However, a better understanding of BIA mechanics is required to interpret the results in which the elderly amputee group showed a higher SMM than the non-amputee group.

BIAs recognize the human body as a cylinder containing electrolytes. The resistance value is proportional to the length of the conductor and inversely proportional to the crosssectional area of the cylindrical conductor. Therefore, the formula for $Z$ (impedance) $=p$ (specific resistivity) $\times L$ (length) $/$ $A$ (cross-sectional area) is established. Since the formula $\mathrm{V}=\mathrm{p} \times \mathrm{L} 2 / \mathrm{Z}$ is formed through $\mathrm{V}$ (volume) $=\mathrm{L} \times \mathrm{A}, \mathrm{Z}=\mathrm{p} \times \mathrm{L} / \mathrm{A}$, $A=p \times L / Z$, the volume of the aqueous solution in the cylinder can be obtained from the resistance and length, and the value obtained by dividing the square of the length by the resistance value is referred to as the impedance index $\left(p \times L^{2} /\right.$ $Z$ ). Since the value corresponding to the length in the human body is the height, and the impedance can be obtained by measurement, the BIA assumes that the human body is an isotropic cylindrical conductor and calculates the body water content for the height by using the impedance index. Since body water accounts for a certain portion of the lean body mass, this figure is used to determine lean body mass.[14, 15] However, the measured length is reduced by attachment of the electrode to the extremities of amputees; hence, the impedance value proportional to the length is also reduced. In fact, since the height entered into the BIA device is longer than the actual value and does not reflect the amputated area, the impedance index value is increased; thus, the calculated lean body mass increases.

To verify these expected results, the BIA results for each area were compared in the 4 groups according to amputation type. Analysis of the muscle mass by area by amputation type revealed that the median lean mass of the amputated leg was highest in this study (Table 4). The reason for the higher muscle mass in the amputated area is the reduced impedance of the amputated area and the higher impedance index resulting from entering a longer height which does not reflect the amputated length, and results in a higher leg 
muscle mass calculation.

Since the whole-body SMM was calculated based on reports in the literature that the skeletal muscle of the arms and legs obtained from the muscle mass measured in the arms and legs accounts for $75 \%$ of the total skeletal muscle mass, $[16,17]$ the muscle mass of the amputated area in amputation patients, which show higher values than actual measurements, was also reflected in the SMM calculations. Therefore, the mean SMM of the amputee group was higher than that of the non-amputee group. Kim et al. reported that DXA results of elderly leprosy survivors showed a reduction in lean muscle mass only in the amputated limbs.[11]

The phase angle is an index that reflects the health status of cells or cell membranes. Increases in the completeness and functionality of the cell membrane structure increase the phase angle, whereas structural damage to the plasma membrane or decreased selective barrier function may reduce the phase angle.[18] In addition, the phase angle value is known to decrease with aging.[19] In this study, the whole-body phase angle values differed significantly among the amputee, non-amputee, and control groups $\left(4.2 \pm 1.2^{\circ}, 4.4 \pm 0.7^{\circ}\right.$, $5.0 \pm 0.85^{\circ}$, respectively; $\mathrm{P}=0.029$ ) (Table 3 ). The right leg, left leg, and phase angle values by area also differed significantly among the 3 groups, indicating the poor health of cell membranes in the amputated areas of elderly patients with leprosy.

The ECW ratio values, reflecting the whole-body edema status, (from high to low) were found in the amputee, nonamputee, and control groups. Valentini et al.[20] reported that edema, a common symptom in reactional states, may occur during the course of leprosy. Stanley et al.[21] reported that 14 patients with leprosy developed edema of the hands and/or feet associated with type-2 lepra reactions (erythema nodosum leprosum) due to lymph node problems. Therefore, leprosy may have affected the ECW ratio values even in patients with long-term diseases. However, a comparison of the 4 groups by amputation levels showed that the ECW ratio of the lower limb amputated area was significantly high (Table 4) and indicative of edema in the amputated leg and may have affected systemic edema. Edema is considered a pathologic accumulation and retention of intracellular and extracellular fluids in response to trauma and a major factor in the long-term rehabilitation of amputation patients. When the patient is sitting or standing, gravity increases the degree of perfusion of the tissues of the lower limbs, resulting in edema.[19] Conversely, the water content is also high near amputated areas, which may lead to the assumption that it increases the ECW ratio measurements, but since the ECW ratio is obtained by ECW/TBW and the factors contributing to edema are reflected in the numerator and denominator, the ECW ratio value itself is not affected by amputation; rather, it reflects the edema status.

Finally, according to the report on developing reference values for Korean adults for BIVA, the X-axis (R/height) of the impedance vector in the BIVA plot reflects the resistance of water. BIVA was used for interpretation of the results, a graphical method also known as $R X_{\mathrm{C}}$, where the resistance and reactance values normalized by height $(H)(R / H$ and $X c / H$, respectively) give rise to an impedance vector and its ellipse of confidence. Therefore, its shifting to the right increases the body's resistance, which implies the body's form is decreasing (becoming cachectic and lean), whereas its shifting to the left implies that the impedance vector is reduced, indicating that the circumference of the human body is increasing (obese or athletic). On the other hand, the $\mathrm{Y}$-axis (Xc/height) reflects the resistance of the cell membranes, so an increase in the $Y$ axis indicates healthy cells and good nutritional status, while a decrease in the Y-axis indicates the opposite.[22] Piccoli et al.[23] examined the change in BIVA plots in hemodialysis patients before vs. after dialysis and reported shifts to the upper right after water was removed. According to the BIVA plot of this study (Fig. 2), the $X_{c}$ /height and R/height values of the elderly amputee with leprosy group were lower than those of the non-amputee group and were mainly located on the lower left side of the graph. This is a result of the $\mathrm{R} /$ height value moving to the left as resistance is reduced in proportion to the amputated length of the lower limb. It also reflects the poor nutritional and cell health status of the amputee vs. non-amputee group.

The purpose of this study was to analyze the body compositions of patients with amputations by performing BIA tests and evaluating the actual extent of expected errors within the BIA test to determine whether the BIA is effective for assessing the muscle mass of patients with amputations. However, due to difficulty recruiting chronic patients with amputations, this study included patients who developed leprosy and lived as disabled amputees. Leprosy has become a rare disease in Korea, and since the majority of affected patients have died and the survivors are mostly elderly, there were only a few participants in this study. Therefore, a major disadvantage existed in the anthropometric measurements of the amputee group in the analysis of the study results by division of the participants into groups according to amputation level. As height and weight are the basic values required for BIAs, it would have been better to reduce the intergroup height and weight differences for the analyses. Another limitation was that the subject was elderly, and because of the discomfort in behavior as a patient with amputated lower extremities, BIA was measured by visiting individual homes, so environmental factors such as temperature, humidity, and time could not be controlled during the measurement.

In further studies, methods such as electrical impedance myography, computed tomography, magnetic resonance imaging, and DXA, which are used to evaluate neuromuscular diseases, should be considered to assess the body composition near amputated areas. There are needed to validate the process of correction of the amputated limb length before BIAs can be used as a viable tool for determining body composition values in amputees. 
In summary, the phase angle, ECW ratio, and BIVA obtained by BIAs were applicable to elderly amputees with leprosy. However, values such as SMM showed higher errors near the amputated areas.

\section{CONFLICTS OF INTEREST}

Jihyun Lee, Seorin Doo, Yeonhee Lee, Jaeyoung Ahn, Yookyoung Park, Sung Soo Hong declare no conflicts of interest. Hyunjoo Shin works for InBody Company, manufacturer of the BIA instrument. Jae-myeong Lee received a research grant from InBody Company to study and validate BIA device use for amputees.

\section{ORCID}

Jihyun Lee, https://orcid.org/0000-0003-0609-9665

Seorin Doo, https://orcid.org/0000-0002-7572-4041

Yeonhee Lee, https://orcid.org/0000-0001-7492-5151

Jaeyoung Ahn, https://orcid.org/0000-0001-6014-4506

Yookyoung Park, https://orcid.org/0000-0002-8536-0835

Hyun Joo Shin, https://orcid.org/0000-0002-8692-4129

Jae-myeong Lee, https://orcid.org/0000-0001-5494-0653

\section{REFERENCES}

1. Baumgartner RN, Chumlea WC, Roche AF. Bioelectric impedance phase angle and body composition. Am J Clin Nutr 1988;48:16-23.

2. Azcue M, Wesson D, Neuman M, Pencharz P. What does bioelectrical impedance spectroscopy (BIS) measure? In: Ellis KJ, Eastman JD, eds. Human body composition: in vivo methods, models, and assessment. Boston: Springer, 1993:121-3.

3. Bioelectrical impedance analysis in body composition measurement: National Institutes of Health Technology Assessment Conference Statement. Am J Clin Nutr 1996;64(3 Suppl):524S-32S.

4. Bae $\mathrm{H}$, Shin JC, Park Cl, Kim YW, Ko YH, Jang JH, et al. Gait analysis of unilateral transfemoral amputees with prosthetics on an inclined surface. J Korean Acad Rehabil Med 2006;30:69-73.

5. Park SK, Lim JH. Clinical characteristics of Sorokdo's Hansen patients having neuropathic ulcer on the plantar region. Korean Lepr Bull 2011;44:27-34.

6. Osterkamp LK. Current perspective on assessment of human body proportions of relevance to amputees. J Am Diet Assoc 1995;95:215-8.

7. Brunnstrom S, Lehmkuhl LD, Smith LK. Brunnstrom's clinical kinesiology. 4th ed. Philadelphia: F.A. Davies, 1983.

8. Fisher SV, Gullickson G Jr. Energy cost of ambulation in health and disability: a literature review. Arch Phys Med Rehabil 1978;59:124-33.

9. Waters RL, Mulroy S. The energy expenditure of normal and pathologic gait. Gait Posture 1999;9:207-31.

10. Rao PS, John AS. Nutritional status of leprosy patients in India. Indian J Lepr 2012;84:17-22.

11. Kim W, Park HW, Hwang BK, Bae SO, Kim IK, Chung SG. Comparison of sarcopenic status between elderly leprosy survivors and general population. Arch Gerontol Geriatr 2014;58:134-9.

12. Eckard CS, Pruziner AL, Sanchez AD, Andrews AM. Metabolic and body composition changes in first year following traumatic amputation. J Rehabil Res Dev 2015;52:553-62.

13. Sherk VD, Bemben MG, Bemben DA. Interlimb muscle and fat comparisons in persons with lower-limb amputation. Arch Phys Med Rehabil 2010;91:1077-81.

14. Heymsfield SB, Wang Z, Visser M, Gallagher D, Pierson RN Jr. Techniques used in the measurement of body composition: an overview with emphasis on bioelectrical impedance analysis. Am J Clin Nutr 1996;64(3 Suppl):478S-84S.

15. Lukaski HC. Methods for the assessment of human body composition: traditional and new. Am J Clin Nutr 1987;46:537-56.

16. Heymsfield SB, Smith R, Aulet M, Bensen B, Lichtman S, Wang J, et al. Appendicular skeletal muscle mass: measurement by dual-photon absorptiometry. Am J Clin Nutr 1990;52:214-8.

17. Snyder WS, Cook MJ, Nasset ES, Karhausen LR, Howells GP, Tipton IH. Report of the task group on reference man. Oxford: Pergamon Press, 1975:109.

18. Jang SY, Kang SW, Choi WA, Lee JW, Suh MR, Lee SM, et al. Nutritional status and body composition in Korean myopathy patients. Clin Nutr Res 2016;5:43-54.

19. Barbosa-Silva MC, Barros AJ, Wang J, Heymsfield SB, Pierson RN Jr. Bioelectrical impedance analysis: population reference values for phase angle by age and sex. Am J Clin Nutr 2005;82:49-52.

20. Valentini A, Nery JA, Salles AM, Vieira LM, Sarno EN. [Edema in leprosy: the clinical and therapeutic aspects]. Rev Soc Bras Med Trop 1999;32:131-8. Portuguese.

21. Stanley JN, Pearson JM, Ridley DB. Episodic edema in type 2 lepra reaction can be caused by transient lymphatic obstruction in the lymph node. Int J Lepr Other Mycobact Dis 1986;54:231-5.

22. Oh HM. Reference values for Bioelectrical Impedance Vector Analysis in Korean adults: a novel approach using the bioelectrical resistance, reactance, and phase angle [thesis]. Daejeon: Eulji University; 2011.

23. Piccoli A. Identification of operational clues to dry weight prescription in hemodialysis using bioimpedance vector analysis. The Italian Hemodialysis-Bioelectrical Impedance Analysis (HD-BIA) Study Group. Kidney Int 1998;53:103643. 